\title{
Protecting Patient Access to Oral Cancer Drugs in the United States
}

\author{
By Steven K. Stranne, MD, JD
}

In Journal of Oncology Practice, Han et al ${ }^{1}$ report on the experiences of Canadian oncologists and hematologists in confronting barriers to access for oral cancer drugs. The experience with oral cancer drugs in the United States is shaped by a number of distinguishing circumstances, including a multipayer insurance system that relies on a mix of public and private sector coverage, the role of state and federal policymakers in establishing patient safeguards for both public and private health insurance, and the degree of regulation and scrutiny focused on the actions of health care professionals. This commentary provides an update on developments in the United States regarding patient access to oral cancer drugs.

\section{Need for Oral Parity}

We are witnessing an increasing number of troubling circumstances throughout the United States in which individuals with health insurance are unable to afford prescribed oral cancer drugs despite coverage of these drugs by their health insurers. In such instances, the insurer would cover the prescribed oral cancer drug, but the aggregate cost-sharing obligations imposed on the individual with cancer (including deductibles, copayments, and coinsurance) render the prescribed oral cancer drug unaffordable. In many of these instances, the cost-sharing burdens for oral cancer drugs are much higher than those that would apply to other cancer drugs administered by a health care professional.

Differences in cost-sharing between oral and intravenous cancer drugs arise under the benefit structures used by many health insurance plans in the United States. The traditional structure of comprehensive health insurance products in the United States includes a medical benefit and an outpatient prescription drug benefit with different rules governing the patient's cost-sharing responsibilities for items and services provided under these two benefits. Most oral drugs—including oral cancer drugs—are covered under the prescription drug benefit of the plan. In contrast, intravenous and injected cancer drugs administered by health care professionals typically are covered under a separate medical benefit that applies to other professional services provided in the outpatient setting. The financial incentives underlying prescription drug benefits are often designed to encourage patients to request less expensive generic drugs whenever possible. Although the cost-sharing requirements for generic drugs may be modest under many prescription drug benefits, the cost-sharing requirements for patients for other types of drugs are often substantially higher under the prescription drug benefit than under the medical benefit. In many instances, although there often is no substantially equivalent generic option to select, the most-expensive oral cancer drugs are placed on tiers within the prescription drug formulary that carry high cost-sharing requirements.
The phrase oral parity is used to refer to legislation designed to help ensure equality in patient cost-sharing burdens between oral and intravenous cancer drugs. Oral parity laws have two primary components. First, the laws establish safeguards to ensure that individuals with cancer can access oral cancer drugs under the same general cost-sharing rules as other cancer drugs, including intravenous and injected cancer drugs. Second, the laws attempt to create safeguards to prevent insurers from circumventing the intent of the legislation by reclassifying intravenous drugs or by using other means.

There is significant progress to report. Legislatures in 20 states and the District of Columbia have enacted oral parity laws for private sector health insurance plans that are subject to state law. This includes six oral parity laws enacted during 2012 and early 2013 in Delaware, Louisiana, Maryland, Massachusetts, Nebraska, New Jersey, and Virginia. ${ }^{2-7}$ Efforts are under way in a number of the remaining states, but there is also a need for safeguards for insurance coverage provided by self-insured employers who generally are not subject to state oral parity laws. A majority of individuals with employer-based health care coverage are covered by self-insured employers, and these health benefits are governed under a federal law called the Employment Retirement Income Security Act (ERISA). ${ }^{8}$ Advocates are working to promote oral parity safeguards under these self-insured plans as well.

Oral parity bills are intended to provide targeted relief to individuals with cancer to improve access and affordability of medically necessary care. As a result, there are no provisions in these laws that involve reimbursement for physicians, pharmacists, or other health care providers. Although oral parity legislation does not address underlying issues involving the prices established for new cancer drugs, these laws provide a tangible and immediate step for protecting access to oral cancer drugs for a vulnerable group of patients.

\section{Safeguards for Oral Cancer Drugs Under Medicare}

The role played by the Medicare program in cancer policy is substantial given that Medicare covers approximately $60 \%$ of all patients with cancer in the United States. ${ }^{9}$ Medicare is the national health insurance program covering individuals who are age $\geq 65$ as well as younger individuals who qualify on the basis of disability. Medicare beneficiaries have the option of enrolling in a prescription drug benefit plan that provides access to a broad scope of oral cancer drugs beyond the handful of oral cancer drugs covered under the traditional benefit.

From the initial implementation of the Medicare prescription drug benefit in 2006, officials at the Centers for Medicare and Medicaid Services (CMS) created subregulatory guidance to protect patient access to oral cancer drugs. Under this safe- 
guard, antineoplastics are a protected class in which "substantially all" drugs must be available to enrollees under the prescription drug formulary. In this context, substantially all ensures access to a formulary with the full scope of unique molecular entities and active ingredients in this drug class. ${ }^{10}$ Congress subsequently enacted legislation recognizing the ongoing need for such protected classes and requiring CMS to establish criteria and procedural safeguards before revising these policies in the future. ${ }^{11,12}$ The Medicare program also provides additional protection for coverage of all drugs used in an anticancer regimen (including oral cancer drugs) by requiring coverage of evidence-based off-label indications, primarily if listed favorably in designated drug compendia.

In the context of private insurance provided under the health exchanges established by the Affordable Care Act, CMS now has the added responsibility of promulgating regulations to define the scope of essential health benefits that must be provided by these private sector plans. In finalizing this regulation, the Obama administration and CMS declined to establish a rule that is as protective as the substantially all safeguard promulgated for Medicare by CMS in the recent past. ${ }^{13}$ Although the new regulations include some requirements regarding the number of drugs that must be covered in each therapeutic class of drugs, there are significant concerns regarding whether sufficient safeguards are in place to protect access to oral and other cancer drugs when no clinically equivalent substitutes exist. Advocates for patients with cancer must be vigilant in monitoring this situation and working with policymakers at both the state and federal levels to help protect affordable access to oral cancer drugs under the health insurance plans that will become available in the exchanges beginning in 2014 .

As with private sector coverage, there are concerns under Medicare Part D regarding the affordability of some oral cancer drugs because of the level of cost sharing imposed on individuals who do not qualify for full or partial financial subsidies. Although CMS has taken steps to limit the coinsurance for drugs in tiers for specialty and injected drugs to only $33 \%$, oral cancer drugs remain subject to even higher coinsurance levels in various ways under the annual out-of-pocket threshold. Even after an individual patient reaches the annual out-of-pocket threshold (\$4,750 in 2013), Medicare Part D enrollees remain responsible thereafter for coinsurance of up to $5 \%$ of the cost of the drug. ${ }^{14,15}$ Thus, there is no absolute cap on an individual's cost-sharing burden for a regimen including expensive oral cancer drugs.

\section{Discussion}

Given the concerns with affordability and oral parity, there is a continuing need for cancer specialists to help educate policymakers regarding the clinical importance of protecting access to oral cancer drugs. Policymakers need to understand that the oral cancer drugs introduced over the past few years often provide significant clinical advantages — not merely convenience. In some instances, oral cancer drugs represent the only viable treatment option for an individual patient. The American Society of Clinical Oncology has endorsed principles and recommendations to promote state and federal laws that mitigate cost-sharing requirements for patients with cancer, ${ }^{16}$ joining patient advocacy groups and other stakeholders in the cancer community to educate policymakers and promote these initiatives.

The challenges facing individuals with cancer and cancer specialists in the United States are not limited to the issues of oral parity and affordability discussed here, but these issues remain hallmarks of the US experience with oral cancer drug access. The experience with oral cancer drugs in the United States is shaped by a number of distinguishing circumstances, including a multipayer insurance system that relies on a mix of public and private sector coverage, the role of state and federal policymakers in establishing patient safeguards for both public and private health insurance, and the degree of regulation and scrutiny focused on the actions of health care professionals. As such, the survey data reported by Han et $\mathrm{al}^{1}$ on the Canadian experience are informative but not generalizable to the United States.

As one additional example of the differences between the United States and Canada, physicians in the United States practice in an environment characterized by extensive scrutiny over the accuracy of information accompanying claims for coverage and reimbursement under both public and private health insurance programs. The need to refrain from generalizing the findings of Han et $\mathrm{al}^{1}$ is particularly applicable to the Canadian survey data on the accuracy of claims information in Canada. In addition to the ethical issues related to accuracy in claims submitted to health insurance programs, physicians in the United States are bombarded with information involving the adverse consequences of inaccurate, inadequate, or misleading medical documentation. Policymakers in the United States have developed a robust system of safeguards and penalties to identify and prevent the submission of false, inaccurate, or unsubstantiated claims information.

The interests of patients are best served when policymakers collaborate with physician experts and other stakeholders in the cancer community to help ensure that individuals with cancer have meaningful and timely access to medically necessary and clinically appropriate services. By working with policymakers in the United States, progress is being made to protect the interests of individuals with cancer, including individuals who require access to oral cancer drugs. As we face a period of ongoing change with respect to the agents available to treat cancer and the structure of the US health insurance system, there remains much work to be done to monitor, identify, and remedy problems involving patient access and affordability to medically necessary cancer therapies, including oral cancer drugs.

\section{Author's Disclosures of Potential Conflicts of Interest}

The author indicated no potential conflicts of interest.

Steven K. Stranne, MD, JD, is with the Washington, DC, office of Polsinelli $P C$.

DOI: 10.1200/JOP.2012.000795; published online ahead of print at jop.ascopubs.org on May 21, 2013. 


\section{References}

1. Han D, Trinkaus M, Hogeveen S, et al: Physician experiences and challenges obtaining unfunded oral chemotherapy across Canada. J Oncol Pract doi: 10.1200/JOP.2012.000680 [epub ahead of print on January 2, 2013]

2. HB 265: An act to amend Title 18 of the Delaware code relating to health insurance coverage for oral and intravenous anticancer medications: 146th General Assembly (DE 2012). http://legis.delaware.gov/LIS/lis146.nsf/vwLegislation/ $\mathrm{HB}+265 /$ file/legis.html?open

3. SB 179: Kathleen A. Mathias chemotherapy parity act of 2012: 430th General Assembly (MD 2012). H.B. 243. http://mgaleg.maryland.gov/2012rs/chapters_ noln/Ch_5_hb0243T.pdf

4. LB 882: An act to require certain cancer treatment coverage as prescribed and to provide a termination date: 102nd Legislature (NE 2012). http:// nebraskalegislature.gov/FloorDocs/102/PDF/Intro/LB882.pdf

5. S. 2363: An act relative to oral cancer therapy (MA 2013). http://www. malegislature.gov/Laws/SessionLaws/Acts/2012/Chapter403

6. S. 1834A/A. 2666: An act concerning health benefits coverage for oral anticancer medications and supplementing various parts of statutory law: 214th Legislature (NJ 2012). http://www.njleg.state.nj.us/2010/Bills/PL11/188_.HTM

7. S6055/A8906: Relates to coverage for oral chemotherapy: 234th Legislature (NY 2012). http://open.nysenate.gov/legislation/bill/A8906-2011

8. Pub Law No. 93-406, as amended: Codified in part at 29 USC $\$ 1002$ et seq

9. Smith BD, Smith GL, Hurria A, et al: Future of cancer incidence in the United States: Burdens upon an aging, changing nation. J Clin Oncol 27:2758-2765, 2009
10. Centers for Medicare and Medicaid Services: Prescription drug benefit manual: Chapter 6-Part D drugs and formulary requirements: Section 30.2.5Revision 2, July 18, 2008. http://www.cms.gov/Regulations-and-Guidance/ Guidance/Transmittals/downloads/R2PDB.pdf

11. Pub L No. 110-275: Medicare Improvements for Patients and Providers Act of 2008, P.L. 110-275. http://www.gpo.gov/fdsys/pkg/PLAW-110publ275/pdf/ PLAW-110publ275.pdf

12. Patient Protection and Affordable Care Act, $\$ 3307$, amending $\$ 1860 D$ of the Social Security Act. P.L. 111-148 http://www.gpo.gov/fdsys/pkg/PLAW111publ148/pdf/PLAW-111publ148.pdf

13. Department of Health and Human Services: Patient Protection and Affordable Care Act: Standards related to essential health benefits, actuarial value, and accreditation-78 Federal Register 12834-12872, February 25, 2013. http:// www.gpo.gov/fdsys/pkg/FR-2013-02-25/pdf/2013-04084.pdf

14. Centers for Medicare and Medicaid Services: Announcement of calendar year (CY) 2013 Medicare advantage capitation rates and medicare advantage and Part D payment policies and final call letter, April 2, 2012, pp 39, 123. http://www. cms.gov/Medicare/Health-Plans/HealthPlansGenlnfo/Downloads/2013-Call-Letter. pdf

15. Social Security Act $\S 1860 D-2(b)$. http://www.socialsecurity.gov/OP_Home/ ssact/title18/1860D-02.htm

16. American Society of Clinical Oncology: Principles for state oral parity legislation http://ascoaction.asco.org/Portals/0/Documents/Oral\%20Chemo\%20Parity\% 20Principles.pdf

\section{Every 5 Minutes Research Published in JCO is Cited in Other Peer-Reviewed Journals}

JCO boasts one of the highest Impact Factors for any cancer journal-18.372-as reported by Thomson Reuters in its 2011 Journal Citation Reports. Total 2011 citations in the scientific literature to JCO exceeded 120,000, ranking JCO as second among oncology journals.

To submit a manuscript, visit submit.jco.org.

To subscribe or activate, visit jco.org/subscriptions. 